\title{
Evolutionary responses of a dominant plant along a successional gradient in a salt-marsh system
}

\author{
Qingqing Chen $\mathbb{D}$
}

Received: 17 January 2021 / Accepted: 1 April 2021/Published online: 15 April 2021

(C) The Author(s) 2021

\begin{abstract}
The ecological responses of plant populations along a successional gradient have been intensively examined; however, the evolutionary responses received much less attention. Here, I explored genetic changes of key phenotypic traits of a dominant clonal plant (Elytrigia atherica) along a saltmarsh successional gradient by collecting samples along the successional gradient in the high and low marsh and growing them in a common environment (greenhouse). Additionally, to explore whether changes in traits are driven by abiotic (e.g. clay thickness) and biotic (e.g. grazing intensity) variables along the successional gradient, I measured these two variables in the field. I found that clay thickness (a proxy of total nitrogen) increased along the successional gradient both in the high and low marsh; grazing intensity from
\end{abstract}

Communicated by Julie C. Zinnert.

Supplementary Information The online version contains supplementary material available at https://doi.org/10.1007/ s11258-021-01137-1.

Q. Chen $(\square)$

Groningen Institute for Evolutionary Life Sciences

(GELIFES), University of Groningen, Nijenborgh 7,

9747 AG Groningen, The Netherlands

e-mail: chqq365@hotmail.com

Present Address:

Q. Chen

Institute of Ecology, College of Urban and Environmental

Science, Peking University, 100871 Beijing, China hares (the most important herbivores) decreased along the successional gradient in the high marsh but did not change in the low marsh. Meanwhile, I found that growth in number of leaves and ramets decreased, while rhizome length increased, along the successional gradient for E. atherica collected from the high marsh. Opposite trends were found for E. atherica collected from the low marsh. Results suggest that, in the high marsh, herbivores may overrule nutrients to drive trait changes. That is, at the early successional stages, E. atherica had higher growth in number of leaves and ramets to compensate for high-intensity grazing. In the low marsh, nutrients may be the dominant driver for trait changes. That is, at the late successional stages, E. atherica had higher growth in number of leaves and ramets but shorter rhizomes to maximize its expansion under the favorable conditions (higher nutrient availability). Results suggest that ecologically important abiotic and biotic variables such as nutrients and herbivores may also have a substantial evolutionary impact on plant populations.

Keywords Evolutionary responses - Genetic differentiation · Herbivores · Nutrients · Traits · Saltmarsh 


\section{Introduction}

Succession is a complex process driven by many abiotic and biotic factors (Ellison 1960; Tillman 1985), it occurs in different ways in different systems (Bazzaz 1979; Huston and Smith 1987). The ecological responses of plant populations and communities along a successional gradient have been intensively examined (Bazzaz 1979; Tilman 1987; Olff et al. 1997; Praclr 1997; Loranger et al. 2016; Schrama et al. 2017). For instance, in a salt-marsh system, a tall late successional plant (Elytrigia atherica) increases in dominance along the successional gradient as sediment accumulates (Olff et al. 1997; Schrama et al. 2017). However, the evolutionary responses of plant populations along a successional gradient received much less attention. Plant populations may become genetically different under different selection pressures, and the resulting variation in phenotypic traits among populations can be evaluated by growing their offspring in a common environment (Billington et al. 1988). Studies show that plant populations can rapidly (years to decades) adapt to different abiotic and biotic environments (Billington et al. 1988; Shaw and Etterson 2012; Didiano et al. 2014; Völler et al. 2017). Adaptive evolution in plant populations can potentially alter species interactions, impact community structure, and ecosystem functioning (Post and Palkovacs 2009; Lavergne et al. 2010). Therefore, it is important to understand the evolutionary responses of plant populations along a successional gradient.

Nutrients, especially nitrogen, usually increase along a successional gradient (Tilman 1987). Increased nitrogen usually leads to species replacement, with nitrogen-loving plants becoming dominant at the late successional stages. However, in many cases, these late successional plants also occur (but not abundant) at early successional stages. As increased nutrients usually shift competition from belowground to aboveground (Hautier et al. 2009), late stage populations may adapt to have a higher growth rate, higher photosynthesis capacity, and larger aboveground biomass. Indeed, Fischer et al. (2011) found that Poa alpina collected from fertilized grasslands had larger aboveground biomass than those collected from unfertilized grasslands when grown in a common garden. However, others found that plants are not responsive to nutrients (fertilization) (e.g. Völler et al. 2017). Generally, few studies have investigated how plant populations adapt to different levels of nutrients, which makes it difficult to draw solid conclusions (Pluess 2013).

Grazing intensity may also change along a successional gradient due to changes in forage plants and their abundances (Chen et al. 2019), which in turn can be an important driver for evolutionary changes in plant populations. So far, studies exploring the evolutionary effects of herbivores on plant populations yield inconsistent results. Some studies show that herbivores drive genetic differentiation (Carman and Briske 1985; Kleijn and Steinger 2002; Veeneklaas et al. 2011; Turley et al. 2013), while others show that the evolutionary effects are not apparent (Pluess 2013). Several reasons may cause this inconsistency. First, different plant species may respond differently to herbivores. For instance, Didiano et al. (2014) found that only one out of four-studied plant species (Festuca rubra, the most abundant species) showed the evolutionary responses (trait differentiation in leaf numbers) in a long-term ( $>20$ years) rabbit exclosure experiment in Silwood Park, England. Second, given that grazing intensity plays an important role in regulating plant communities ecologically (Wang and Tang 2019), their evolutionary effects may also only become apparent when grazing intensity is high. However, to my knowledge, the evolutionary responses of plant populations to grazing intensity along a successional gradient has rarely been studied.

Elytrigia atherica (synonym Elymus athericus) is a widespread European saltmarsh grass, particularly dominant in the high marsh. This grass has strongly expanded to the lower and younger marshes (Pétillon et al. 2005; Milotić et al. 2010; Veeneklaas et al. 2013; Wanner et al. 2014; Rupprecht et al. 2015; Van Klink et al. 2016). As a result, it has led to a decline in plant diversity in saltmarshes across Europe (Esselink 2017). Investigating the evolutionary responses of this grass along the successional gradient would improve our understanding of the underlying mechanisms for its rapid expansion, which may shed light on maintaining higher biodiversity and ecosystem functioning in many European saltmarshes. Bockelmann et al. (2003) found that genotype diversity is high in this grass, and genetic differentiation (isolation-bydistance) is present at large spatial scales in several Wadden Sea saltmarshes. Reciprocal transplantation also confirmed adaptation of this grass to its site origin at one of the Wadden Sea saltmarsh (Bockelmann 
et al. 2011). That is, seeds collected from the high marsh at the old successional stage performed better in the high marsh of the old successional stage than the young stage in the field. However, a study in the same saltmarsh found weak genetic differentiation of this grass between two intermediate successional stages (Scheepens et al. 2007). Because these inconsistent results are based on a few successional stages with different approaches, the evolutionary responses of this grass along a successional gradient remain unclear.

A well-calibrated natural successional gradient (perpendicular to marsh platform elevation) is present in the saltmarsh of the island of Schiermoonikoog (Olff et al. 1997). Both clay thickness (a proxy of total nitrogen) and grazing intensity vary along the successional gradient (Kuijper and Bakker 2005; Schrama et al. 2012, 2017; Chen et al. 2019). The ecological responses of plant populations and communities along this successional gradient have been examined intensively. For instance, E. atherica increases in dominance along the successional gradient, while plant diversity peaks at the intermediate stages (Schrama et al. 2017). The evolutionary responses E. atherica have also been investigated at a few successional stages (Bockelmann et al. 2003, 2011; Scheepens et al. 2007). However, a general pattern of the evolutionary responses of this grass along the successional gradient in the high and low marsh is unknown. Chen (2020) found that $E$. atherica collected from the high and low marsh show trait differentiation when grown in a greenhouse. Additionally, Bockelmann et al. (2003) found that genetic differentiation of $E$. atherica between the high and low marsh $(<100 \mathrm{~m})$ within sites is even stronger than genetic differentiation among different sites (60-443 km). Indeed, many processes are different in the high and low marsh such as inundation frequency in the low marsh can be 2-5 times higher than that in the high marsh (Bockelmann et al. 2003). Therefore, I expected that changes in nutrients and grazing intensity along the successional gradient would be different in the high and low marsh. Subsequently, the evolutionary responses of $E$. atherica along the successional gradient would be different in the high and low marsh.

\section{Materials and methods}

Study site

A natural successional gradient, spanning 120 years, is present in the back-barrier saltmarsh of the island of Schiermonnikoog $\left(53^{\circ} 30^{\prime} \mathrm{N}, 6^{\circ} 10^{\prime} \mathrm{E}\right)$, the Netherlands. Height of the mudflats and saltmarsh (till the dunes area) ranges from 35 to $200 \mathrm{~cm}+$ MHW (mean high tide). The lower saltmarsh is inundated several hundred times per year, whereas the high saltmarsh (low dunes) is inundated ca. once per year (Bakker 1989). The eastern part of the island is younger than the western part, naturally separated by creeks (Olff et al. 1997). Different successional stages are categorized based on the time of vegetation establishment by checking the aerial photograph (Olff et al. 1997) and justified by monitoring vegetation succession and key soil parameters in permanent plots at each successional stage (Schrama et al. 2017). Note, in this study, successional stages were counted till 2016 when the samples were taken. For instance, stage 20 in the eastern part of the saltmarsh indicates that vegetation was established in this area in 1996. The eastern part of the saltmarsh (the sampling area) is only grazed by small herbivores, including spring staging Brent Geese (Branta bernicla), Barnacle Geese (Branta leucopsis), year-round present Brown hares (Lepus europaeus), and rabbits (Oryctolagus cunniculus). Hares are the most important herbivores, while rabbits are rare in this system (Kuijper and Bakker 2005; Chen et al. 2019).

Field investigation of clay thickness and droppings

Clay thickness and grazing intensity were measured in 2016 (Chen et al. 2019), detailed procedure has been described elsewhere (Chen et al. 2019). Here I provide a brief description. A line transect was set up at successional stage 20, 30, 40, 60, and 120 in 2016. Each line transect consisted of $204-\mathrm{m}^{2}$ plots, with at least $10 \mathrm{~m}$ distance between one another (Fig. 1). Elevation of these $4-\mathrm{m}^{2}$ plots was measured using Trimble R8 (RD system; precision for elevation 1-2 cm). Following (Olff et al. 1997), I refer the high marsh to elevation $\geq 1.6 \mathrm{~m}+\mathrm{NAP}$ (Normal Amsterdam Water Level), while low marsh to elevation $<1.6 \mathrm{~m}+\mathrm{NAP}$. In total, $244-\mathrm{m}^{2}$ plots were recorded in the high marsh and 76 in the low marsh (4, 


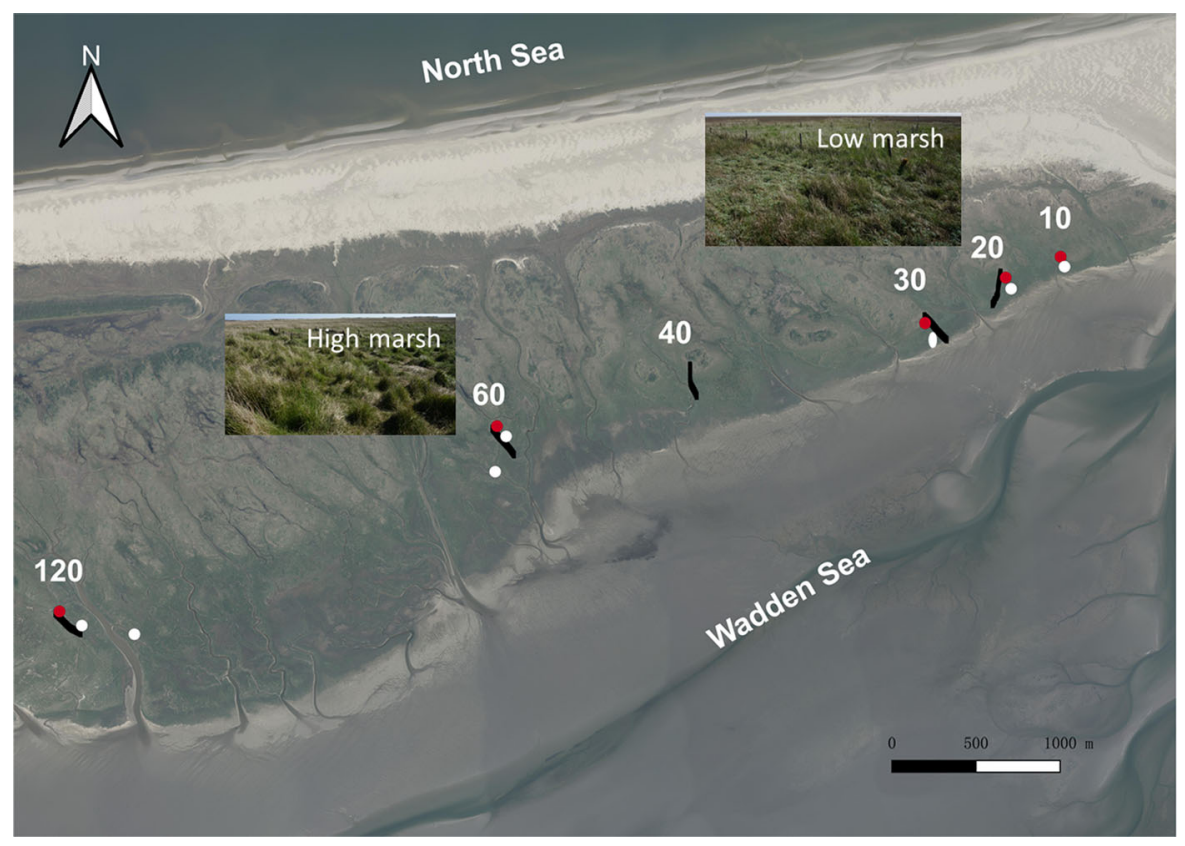

Fig. 1 Sampling location along the successional gradient in the high and low marsh of the island of Schiermonnikoog, the Netherlands. Ages of the successional stages are counted from the year vegetation established to 2016. Dots represent blocks, the red ones are in the high marsh, the white ones are in the low

3, 6, 2, 9 in the high marsh, 16, 17, 14, 18, 11 in the low marsh at stage 20,30,40,60, and 120, respectively). Clay thickness is a good indicator of soil total nitrogen and was measured using a $2 \mathrm{~cm} \varnothing$ soil corer with tick marks $(n=4)$. Number of droppings is a good indicator of grazing intensity (Van Der Wal et al. 2000; Kuijper and Bakker 2005). Droppings from hares and geese were counted and removed within these $4-\mathrm{m}^{2}$ plots every two or three weeks for the whole year in 2016 (May 2016 to April 2017). For each $4-\mathrm{m}^{2}$ plot, hare and goose droppings from the whole year were summed up.

\section{Sampling}

In the high marsh, E. atherica forms continuous meadows, while in the low marsh, E. atherica mainly occurs in patches, particularly at the early successional stages. Samples were taken at similar elevation along the successional gradient in the high $(1.73 \pm 0.0189$; $\mathrm{m}+\mathrm{NAP})$ and low marsh $(1.43 \pm 0.009 ; \mathrm{m}+$ NAP). In April-May 2016, 3 blocks were selected randomly (distance between blocks $>20 \mathrm{~m}$ ) in the high and low marsh per stage. Within each block, 3 marsh, black lines are transects set up for evaluating characteristics along the successional gradient (see Figs. 2, 3). A picture of the low marsh and high marsh at stage 20 and 60 , respectively, are shown

plots were selected (diameter ca. $0.1 \mathrm{~m}$ ) and samples of E. atherica were collected. No samples were collected in the low marsh of stage 20 because there were too few individual stems of $E$. atherica present. Additional samples were taken in the low marsh of the intermediate and late stage (sampling location see Fig. 1). Genotype diversity is high in this grass, Chen (2020) shows that individual stems collected from different plots in most cases belong to different genotypes, and individual stems collected within the plots possibly are also different genotypes.

Greenhouse experiment

Individual stems of $E$. atherica collected from the field were standardized to 1 shoot of $1-2 \mathrm{~cm}$ and 2 roots of $1-2 \mathrm{~cm}$ each before planting. Individual stems were grown together to produce more ramets from May to August 2016 and to reduce carry-over effects (Roach and Wulff 1987). These individual stems were grown in plastic pots $(14.5 \mathrm{~cm}$ in diameter $)$ filled with sand and watered with $1 / 4$ Hoagland solution 1-2 times per week. 


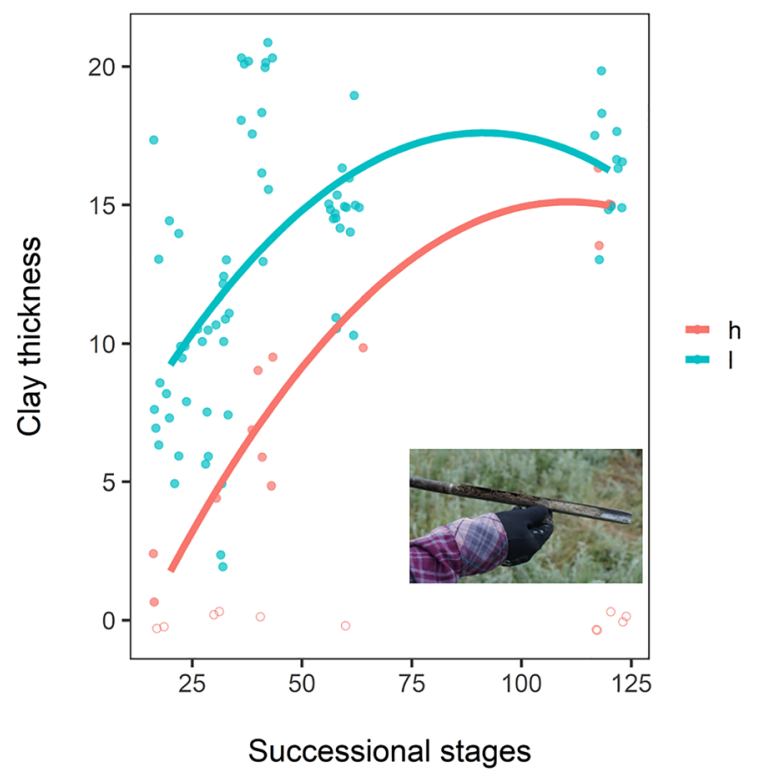

Fig. 2 Clay thickness along the successional gradient in the high and low marsh. Dots are clay data in each $4-\mathrm{m}^{2}$ plot in the transect at each successional stage. Dots are jittered to prevent overlapping. Red open dots are 4- $\mathrm{m}^{2}$ plots where no clay layer was recorded because they were in the dune area. These data were not included in the analysis. The model summary can be found in Table S2

On 7 August 2016, aboveground parts of all pots were harvested. Individual stems were standardized again in the same way. 3-7 individual stems originated from each plot were randomly selected for this experiment. Each standardized sample was grown in the center of a plastic pot $(9 \times 9 \times 10 \mathrm{~cm}$; length $\times$ width $\times$ height) filled with cleaned sand. Pots were randomly arranged into trays (usually 24 pots per tray). One week after, dead samples (e.g. without new green shoots) were discarded; in total, 268 samples survived (see Table S1 for sample size). Each pot received $50 \mathrm{ml} 1 \frac{1}{4}$ Hoagland solution once per week. In addition, water level was kept at $1 \mathrm{~cm}$ (in the trays) to make sure E. atherica did not suffer from drought. All the pots were rearranged every month to randomize their position in the trays and the greenhouse. The greenhouse was maintained at $17{ }^{\circ} \mathrm{C}$ (day) and $14{ }^{\circ} \mathrm{C}$ (night), a photosynthetic photon flux density (PPFD) of $439 \pm 6.91 \mu \mathrm{mol} \mathrm{m} \mathrm{m}^{-2} \mathrm{~s}^{-1}$ for $12 \mathrm{~h}$, and relative air humidity of $70 \%$.

\section{Leaf area and chlorophyll fuorescence}

To look at whether E. atherica adapted along the successional gradient in photosynthesis capacity, I measured the maximum length and width of the leaves in October 2016 in the greenhouse. I calculated leaf area as leaf length times leaf width. I selected the third leaf (i.e. fully grown) from the top of a randomly chosen ramet for this measurement. Later, the same leaves were used for measuring chlorophyll fluorescence using the Portable Chlorophyll Fluorometer PAM-2100. The quantum efficiency (ФPSII), qP, the maximum quantum efficiency of PSII (Fv/Fm), and the NPQ were measured. DPSII is the most useful parameter for the efficiency of Photosystem II. qP indicates the proportion of PSII reaction centers that are open. The maximum quantum efficiency of PSII indicates the quantum efficiency of the open photosystem II centers and is widely used as a reliable indicator of photoinhibition. The maximum quantum efficiency of PSII was measured on leaves darkadapted for ca. 10 min using leaf-clips. NPQ measures change in heat dissipation relative to the dark-adapted state (Maxwell and Johnson 2000).

\section{Phenotypic traits and biomass}

Height of the tallest ramet, number of leaves, and number of ramets were measured for each pot on 15 August, 19 August, 10 September, 22 September, 8 October, and 9 November 2016 (12, 16, 26, 38, 50, 67, and 98 days after planting). After measuring these variables on 9 November, all aboveground parts were cut in each pot at the soil level. Length of each stolon (cm) was measured. Similarly, rhizomes were separated from roots, and length of each rhizome $(\mathrm{cm})$ was measured. Shoots, roots, and rhizomes were dried in the oven $\left(70{ }^{\circ} \mathrm{C}\right)$ to constant weight. Dried biomass was measured to the nearest $0.01 \mathrm{~g}$. Total biomass was the sum of shoot, root, and rhizome biomass. As stolons and rhizomes are structurally and functionally similar, I grouped them and referred them to "rhizomes" hereafter. 


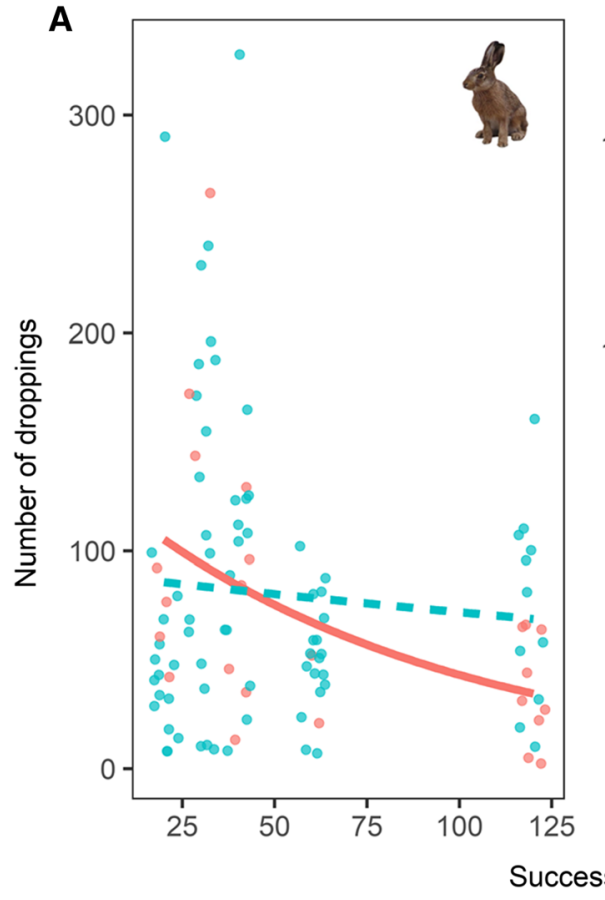

Fig. 3 Hare (A) and goose droppings (B) along the successional gradient in the high and low marsh. Dots are summed whole year dropping data from each $4-\mathrm{m}^{2}$ plot in the transect at each successional stage. Dots are jittered to prevent overlapping.

\section{Data analysis}

\section{Clay thickness}

To check whether clay thickness change along the successional gradient in the high and low marsh (marsh type), I fitted the following model: Im (clay thickness $\sim$ marsh type $*$ successional stage + marsh type $* \mathrm{I}\left(\right.$ successional stage $\left.^{2}\right)$. Including a quadratic term significantly improved model fit than excluding it (judging by AIC). In $114-\mathrm{m}^{2}$ plots in the high marsh, I did not record a clay layer due to that those $4-\mathrm{m}^{2}$ plots were in the dune area. These $114-\mathrm{m}^{2}$ plots were not included in the analysis but were shown in the figure.

\section{Droppings}

I fitted number of droppings from hares and geese separately. For hare droppings, I used generalized linear models $(\mathrm{glm})$ with family of poisson. This model is specified as glm (hare droppings $\sim$ marsh type* successional stage). Including a quadratic term

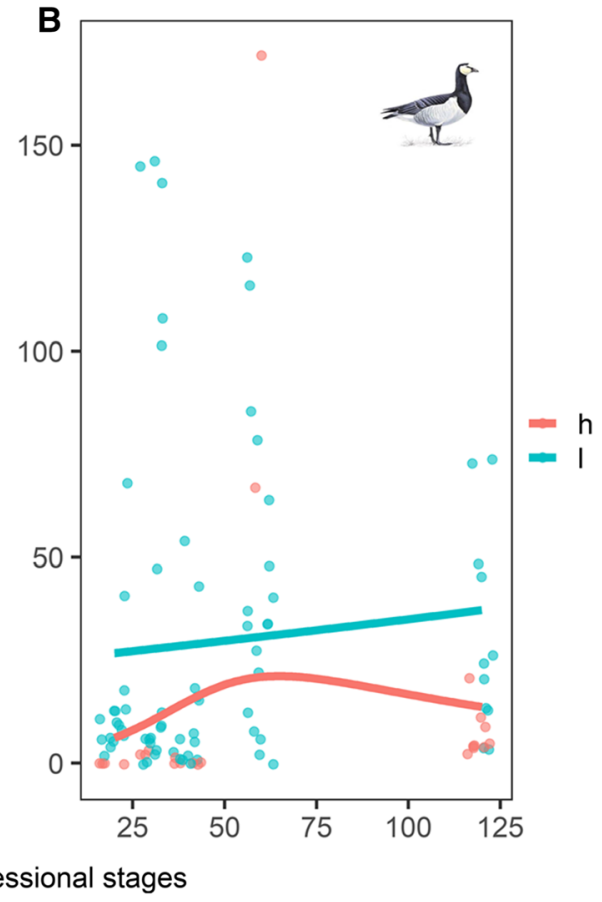

Solid lines represent significant effects of successional stage, dashed line represents non-significant effects of successional stage. The model summary can be found in Table S3

of successional stage did not significantly improve model fit (judging by AIC), so it was not included in the final model. For goose droppings, because there were many zeros (goose droppings were not present in 13 of $1004-\mathrm{m}^{2}$ plots), I fitted these data with a zeroinflated model using the function "zeroinfl" from the R package "pscl" (Zeileis et al. 2008). This model is specified as zeroinfl(goose droppings $\sim$ marsh type * successional stage, dist $=$ "poisson").

Traits along the successional gradient

Growth in height, number of ramets, and number of leaves were the coefficients extracted from generalized linear models (gls) fitting height, number of ramets, and number of leaves over time $(12,16,26,38$, 50, 67, and 98 days after planting) for each sample. Specifically, these variables were fitted using the function "gls" from the R package "nlme" (Pinheiro et al. 2017), with an autocorrelation (corAR1) structure to account for temporal dependence of the data. To reduce spatial dependence of the sampling, I averaged trait data across plots in each block at each 


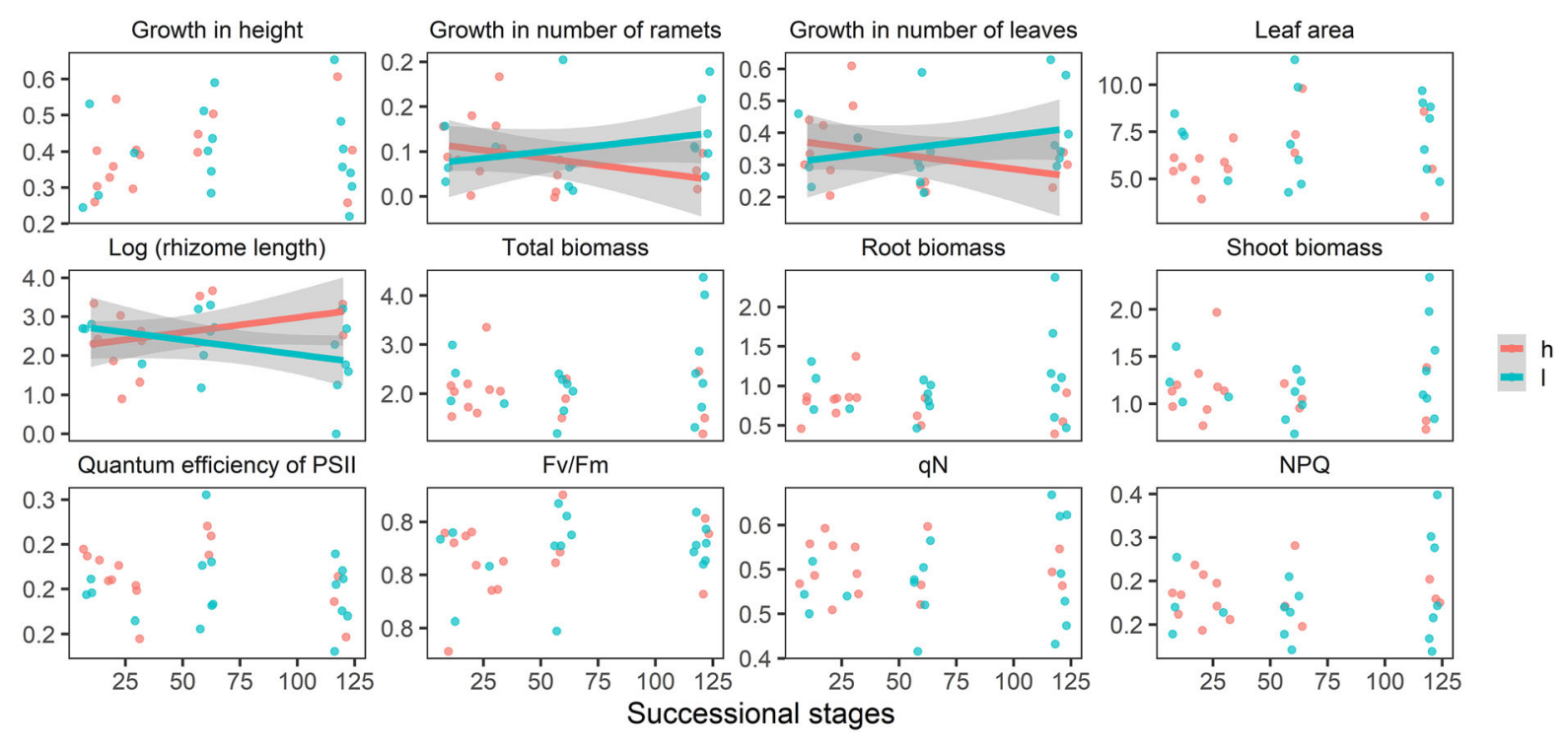

Fig. 4 Traits of Elytrigia atheria collected along the successional gradient in the high and low marsh grown in the greenhouse. Dots are trait data in each block (averaged over plots) at each successional stage to reduce spatial dependence of the sampling. Dots are jittered to prevent overlapping. Detailed

successional stage (see Table S1 for sample size), I then fitted these averaged trait data in the models. The models were specified as $1 \mathrm{~m}$ (trait data $\sim$ marsh type*successional stage). I also tried to include a quadratic term of successional stage, but including it did not improve model fit, therefore, the quadratic term was not included in the final model. Rhizome length was $\log (x+1)$ transformed before fitting the models to improve normality and homogeneity of variance. Due to small sample size, I define that the effects are significant when $p<0.1$. Data analysis was performed using R 3.5.3 (R Core Team 2020).

\section{Results}

Clay thickness

Clay thickness increased along the successional gradient both in the high and low marsh (Table S2; Fig. 2).

\section{Droppings}

Hare droppings decreased along the successional gradient in the high marsh, but did not change in the sample size can be found in Table S1. Lines show significant interaction effects of successional stage and marsh type (high and low; $p<0.1$ ). The model summaries can be found in Table S4

low marsh (significant interaction effects of successional stage and marsh type; Fig. 3a; Table S3). Goose droppings peaked at the intermediate stages in the high marsh, increased slightly along the successional gradient in the low marsh (significant interaction effects of successional stage and marsh type; Fig. 3b; Table S3).

\section{Traits}

The effects of successional stage, and its interaction with marsh type were not significant for 9 of the 12 traits measured. The interaction effects of successional stage and marsh type were significant on growth in number of leaves, growth in number of ramets, and rhizome length (Table S4). Specifically, for E. atherica samples collected from the high marsh, growth in number of leaves and ramets decreased, while rhizome lengths increased along the successional gradient. In contrast, for E. atherica samples collected from the low marsh, growth in number of leaves and ramets increased, while rhizome length decreased along the successional gradient (Fig. 4). 


\section{Discussion}

In the field, I found that both nutrients (using clay thickness as a proxy) and grazing intensity (using hare and goose droppings as an index) changed along the successional gradient in the high and low marsh. In the greenhouse experiment, I found that 3 out of the 12 key functional traits of the dominant grass (Elytrigia atherica) collected from the high and low marsh changed along the successional gradient. These changes in traits may be correlated with changes in nutrients and grazing intensity along the successional gradient.

Nutrients measured as clay thickness increased along the successional gradient both in the high and low marsh. Increased nutrients usually alleviate belowground competition (Hautier et al. 2009), thus populations (genotypes) with higher shoots, larger aboveground biomass (light competitors) are likely to be promoted (Fischer et al. 2011). Additionally, clonal plants can proliferate in nutrient-rich conditions by shortening rhizome length while increasing number of ramets to consolidate their occupation and exploitation of the favorable environment. Conversely, in nutrient-poor conditions, clonal plants increase rhizome length while decreasing number of ramets to increase the probability of escape into a more favorable environment (Slade and Hutchings 1987). Indeed, such changes in traits were observed in E. atherica collected from the low marsh but not the high marsh. Possibly the effects of nutrients in the high marsh were overruled by the effects of herbivores. Similarly, Völler et al. (2017) found that 8 common grassland plants are least responsive to fertilization (nutrients) compared with herbivores and mowing in Germany. Competition from neighboring plants may driver evolutionary changes in functional traits of plant species (Zuppinger-Dingley et al. 2014). Thus, change in plant diversity along the successional gradient in the low marsh may contribute to trait changes in $E$. atherica (Schrama et al. 2017). Plant diversity peaks at the intermediate successional stages in the low marsh in this system (Schrama et al. 2017), however, traits of E. atherica from the intermediate stages did not show strong differences from that of the early and late stages. It suggests that increasing nutrients may be the dominant driver for trait changes along the successional gradient in the low marsh.
Previous studies in this system found that hares and geese slowed down plant species decline via suppressing the expansion of the tall late successional grass, E. atherica, for at least 22 years at the early stage (Chen et al. 2019). Hares and geese do so via impeding the survival of their seedlings (Kuijper et al. 2004). In general, adult plants of E. atherica are not preferred by hares and geese, but seedlings are still consumed considerably (Kuijper et al. 2004; Fokkema et al. 2016). Although hares and geese tended to be present more often in the low marsh (Fig. 3), grazing intensity from hares did not change, while grazing intensity from geese increased slightly along the successional gradient in the low marsh. In this system, hares play a more important role in structuring plant communities, because hares are present all year round, while geese only stay for few months (Kuijper and Bakker 2005). Therefore, although grazing intensity from geese increased along the successional gradient in the low marsh, the effects from geese may not be strong. In the high marsh, hare droppings decreased along the successional gradient, while goose droppings were highest at the intermediate stages. Interestingly, growth in number of leaves and ramets of $E$. aherica collected from the high marsh was highest at the early successional stages, which may be a result of the defense evolution against high grazing intensity. McNaughton (1984) suggested that herbivores drive plants to evolve short, dense, and abundant leaves to prevent apical meristems from being damaged. Growing faster and more ramets can also be an effective way to compensate for biomass reduction under grazing (Van Der Graaf et al. 2005). Turley et al. (2013) showed that Rumex acetosa L. evolves a decreased growth rate in the absence of rabbit grazing using long-term herbivore exclosures from Silwood Park. Rhizome length changed in the opposite direction to that of the growth in number of leaves and ramets along the successional gradient. This could be a trade-off among traits. When plants allocate more biomass to growth (leaves and ramets), they may allocate less to vegetative reproduction (rhizomes). Thus, the ecologically important driver (herbivory) may also have a substantial evolutionary impact on $E$. atherica in this system.

These observed patterns of trait changes along the successional gradient in the high and low marsh are likely due to changes in allele or genotype frequency. In this system, seedlings of E. atherica recruited via 
seeds were rarely observed in the field (Veeneklaas et al., 2011), suggesting that clonal growth was the primary reproduction mode. However, sexual reproduction may occur occasionally via windows of opportunity, which created genetic and genotype diversity. Indeed, genotype diversity is high in this grass (Bockelmann et al. 2003; Veeneklaas et al. 2011; Chen 2020). Increased genotype diversity can increase intraspecific trait variation (Evans et al. 2016), and thus may increase the potential for adaptation. The lifespan of E. atherica is unknown so far. However, De Witte and Stöcklin (2010) indicated that clonal grasses (genets) are usually long-lived plants (hundreds to thousands of years old), therefore adaptive evolution may also happen through clonal lineage selection (Didiano et al. 2014). Maternal effects may also contribute to the trait changes observed here because I grew E. atherica collected from the field for a relatively short amount of time (3 months) before the greenhouse experiment (Roach and Wulff 1987). However, Weiner et al. (1997) suggest that maternal effects are relatively small and short-lived ( $<8$ weeks). Therefore, changes in allele or genotype frequency may play a more important role. Further analyses incorporating genetic data are needed to consolidate these results.

Of the 12 traits investigated, 3 of them show evolutionary responses along the successional gradient. Surprisingly, height and aboveground biomass did not change along the successional gradient despite these 2 traits usually increase along the successional gradient in the field (Dujardin et al. 2011). Völler et al. (2017)_-growing 8 plant species collected from 3 regimes of Germany in a common garden —also found that height and biomass are not responsive to fertilization but they decrease as grazing intensity increases. Shorter and smaller plants are usually less susceptible to herbivores (Díaz et al. 2007). However, Didiano et al. (2014) found that plant height does not necessarily show evolutionary responses to grazing. The ecological responses of photosynthesis performance of plant populations along a succession gradient are often studied (Bazzaz 1979), but the evolutionary responses are less often examined. Here I show that photosynthesis performance generally does not change along the successional gradient. These results suggest that ecologically responsive traits do not necessarily show evolutionary responses along a successional gradient.
In this study, growing E. atherica collected along the successional gradient in the high and low marsh in a common greenhouse, I explored the evolutionary responses of this grass to changing nutrients and grazing intensity along the successional gradient. I found that growth in number of leaves and ramets decreased along the successional gradient in the high marsh, which may be a result of defense evolution against changing grazing intensity. In the low marsh, growth in number of leaves and ramets increased along the successional gradient, which may be an evolutionary response to increasing nutrients. These results suggest that ecologically important biotic and abiotic variables may also impose a substantial evolutionary impact on plant populations.

Acknowledgements I thank Jacob Hogendorf for taking care of the plants in the greenhouse. I thank Natuurmonumenten for offering me the opportunity to work in the saltmarsh of the island of Schiermonnikoog. I thank Ron Snijders for his constructive comments for improving the text and grammar of the manuscript. I thank two anonymous reviewers for their constructive comments and suggestions. QC is funded by CSC (China Council Scholarship).

Author contributions QC conceived the ideas for this manuscript, completed the field, greenhouse, and laboratory work, completed the analyses, and wrote the manuscript.

Data availability Data will be deposited in Dryad Digital Repository once the manuscript gets accepted.

Code availability $\mathrm{R}$ code of all analyses will be available in GitHub once the manuscript gets accepted.

\section{Declarations}

Conflict of interest The authors declare no conflict of interest.

Open Access This article is licensed under a Creative Commons Attribution 4.0 International License, which permits use, sharing, adaptation, distribution and reproduction in any medium or format, as long as you give appropriate credit to the original author(s) and the source, provide a link to the Creative Commons licence, and indicate if changes were made. The images or other third party material in this article are included in the article's Creative Commons licence, unless indicated otherwise in a credit line to the material. If material is not included in the article's Creative Commons licence and your intended use is not permitted by statutory regulation or exceeds the permitted use, you will need to obtain permission directly from the copyright holder. To view a copy of this licence, visit http://creativecommons.org/licenses/by/4.0/. 


\section{References}

Bakker JP (1989) Nature management by grazing and cutting: on the ecological significance of grazing and cutting regimes applied to restore species-rich grassland communities in the Netherlands. University of Groningen, Kluwer Academic Publishers, Dordrecht

Bazzaz FA (1979) The physiological ecology of plant succession. Annu Rev Ecol Syst 10:351-371. https://doi.org/10. 1146/annurev.es.10.110179.002031

Billington HL, Mortimer AM, McNeilly T (1988) Divergence and genetic structure in adjacent grass populations. 1. Quantitative genetics. Evolution (N Y) 42:1267-1277. https://doi.org/10.2307/2409010

Bockelmann AC, Reusch TBH, Bijlsma R, Bakker JP (2003) Habitat differentiation vs. isolation-by-distance: the genetic population structure of Elymus athericus in European salt marshes. Mol Ecol 12:505-515. https://doi.org/ 10.1046/j.1365-294X.2003.01706.x

Bockelmann AC, Wels T, Bakker JP (2011) Seed origin determines the range expansion of the clonal grass Elymus athericus. Basic Appl Ecol 12:496-504. https://doi.org/10. 1016/j.baae.2011.07.003

Carman JGG, Briske DDD (1985) Morphologic and allozymic variation between long-term grazed and non-grazed populations of the bunchgrass Schizachyrium scoparium var. frequens. Oecologia 66:332-337

Chen Q (2020) Low-marsh ecotypes of a dominant plant may not be better adapted to increased sea level. Flora 273:151722. https://doi.org/10.1016/j.flora.2020.151722

Chen Q, Howison RA, Bakker JP, Alberti J, Kuijper DPJ, Olff H, Smit C (2019) Small herbivores slow down species loss up to 22 years but only at early successional stage. J Ecol 107:2688-2696. https://doi.org/10.1111/1365-2745.13236

De Witte LC, Stöcklin J (2010) Longevity of clonal plants: why it matters and how to measure it. Ann Bot 106:859-870. https://doi.org/10.1093/aob/mcq191

Díaz S, Lavorel S, McIntyre S, Falczuk V, Casanoves F, Milchunas DG, Skarpe C, Rusch G, Sternberg M, NoyMeir I, Landsberg J, Zhang W, Clark H, Campbell BD (2007) Plant trait responses to grazing - a global synthesis. Glob Chang Biol 13:313-341. https://doi.org/10.1111/j. 1365-2486.2006.01288.x

Didiano TJ, Turley NE, Everwand G, Schaefer H, Crawley MJ, Johnson MTJ (2014) Experimental test of plant defence evolution in four species using long-term rabbit exclosures. J Ecol 102:584-594. https://doi.org/10.1111/1365-2745. 12227

Dujardin G, Bureau F, Decaëns T, Langlois E (2011) Morphological and reproductive responses of dominant plant species to local conditions in herbaceous successional stages of a calcareous hillside. Flora Morphol Distrib Funct Ecol Plants 206:1030-1039. https://doi.org/10.1016/j.flora. 2011.05.012

Ellison L (1960) Influence of grazing on plant succession of Rangelands. Bot Rev 26:1-78

Esselink P (2017) Wadden sea quality status report. Wadden Sea Ecosyst 9

Evans SM, Sinclair EA, Poore AGB, Bain KF, Vergés A (2016) Genotypic richness predicts phenotypic variation in an endangered clonal plant. PeerJ 2016:1-24. https://doi.org/ 10.7717/peerj.1633

Fischer M, Weyand A, Rudmann-Maurer K, Stöcklin J (2011) Adaptation of Poa alpina to altitude and land use in the Swiss Alps. Alp Bot 121:91-105. https://doi.org/10.1007/ s00035-011-0096-2

Fokkema W, de Boer W, van der Jeugd HP, Dokter A, Nolet BA, De Kok LJ, Elzenga JTM, Olff H (2016) The nature of plant adaptations to salinity stress has trophic consequences. Oikos 125:804-811. https://doi.org/10.1111/oik. 02757

Hautier Y, Niklaus PA, Hector A (2009) Competition for light causes plant biodiversity loss after eutrophication. Science 324:636-638. https://doi.org/10.1126/science.1169640

Huston M, Smith T (1987) Plant succession: life history and competition. Am Nat 130:168-198. https://doi.org/10. 1086/285850

Kleijn D, Steinger T (2002) Contrasting effects of grazing and hay cutting on the spatial and genetic population structure of Veratrum album, an unpalatable, long-lived, clonal plant species. J Ecol 90:360-370

Kuijper DPJ, Bakker JP (2005) Top-down control of small herbivores on salt-marsh vegetation along a prouctivity gradient. Ecology 86:914-923

Kuijper DPJ, Nijhoff DJ, Bakker JP (2004) Herbivory and competition slow down invasion of a tall grass along a productivity gradient. Oecologia 141:452-459. https://doi. org/10.1007/s00442-004-

Lavergne S, Mouquet N, Thuiller W, Ronce O (2010) Biodiversity and climate change: integrating evolutionary and ecological responses of species and communities. Annu Rev Ecol Evol Syst 41 (1):321-350

Loranger J, Blonder B, Garnier É, Shipley B, Vile D, Violle C (2016) Occupancy and overlap in trait space along a successional gradient in mediterranean old fields. Am J Bot 103:1050-1060. https://doi.org/10.3732/ajb.1500483

Maxwell K, Johnson GN (2000) Chlorophyll fluorescence-a practical guide. J Exp Bot 51:659-668. https://doi.org/10. 1093/jexbot/51.345.659

McNaughton SJ (1984) Grazing lawns: animals in herds, plant form, and coevolution. Am Nat 124:863-886

Milotić T, Erfanzadeh R, Pétillon J, Maelfait JP, Hoffmann M (2010) Short-term impact of grazing by sheep on vegetation dynamics in a newly created salt-marsh site. Grass Forage Sci 65:121-132. https://doi.org/10.1111/j.13652494.2009.00725.x

Olff H, De LJ, Bakker JP, Platerink RJ, Van Wijnen HJHJ, De Leeuw J, Bakker JP, Platerink RJ, Van Wijnen HJHJ (1997) Vegetation succesion and herbivory in a salt marsh: changes induced by sea level rise and silt deposition along an elevation gradient. J Ecol 85:799-814. https://doi.org/ $10.2307 / 2960603$

Pétillon J, Ysnel F, Canard A, Lefeuvre JC (2005) Impact of an invasive plant (Elymus athericus) on the conservation value of tidal salt marshes in western France and implications for management: responses of spider populations. Biol Conserv 126:103-117. https://doi.org/10.1016/j. biocon.2005.05.003

Pinheiro J, Bates D, DebRoy S, Sarkar D, Team R-C (2017) nlme: linear and nonlinear mixed effects models. R Packag version $31-131$ 
Pluess AR (2013) Meta-analysis reveals microevolution in grassland plant species under contrasting management. Biodivers Conserv 22:2375-2400. https://doi.org/10.1007/ s10531-013-0528-y

Post DM, Palkovacs EP (2009) Eco-evolutionary feedbacks in community and ecosystem ecology: interactions between the ecological theatre and the evolutionary play. Philos Transe Royal Soc B Biol Sci 364 (1523):1629-1640

Praclr K (1997) Changes in species traits during succession: a search for pattern. Oikos 79:201-205. https://doi.org/10. $2307 / 3546109$

R Core Team (2020) R: a language and environment for statistical computing, Vienna, Austria

Roach DA, Wulff RD (1987) Maternal effects in plants. Annu Rev Ecol Syst 18(18):209-235

Rupprecht F, Wanner A, Stock M, Jensen K (2015) Succession in salt marshes-large-scale and long-term patterns after abandonment of grazing and drainage. Appl Veg Sci 18:86-98. https://doi.org/10.1111/avsc.12126

Scheepens JF, Veeneklaas RM, Van De Zande L, Bakker JP (2007) Clonal structure of Elytrigia atherica along different successional stages of a salt marsh. Mol Ecol 16:1115-1124. https://doi.org/10.1111/j.1365-294X.2006. 03213.x

Schrama M, Berg MP, Olff H (2012) Ecosystem assembly rules: the interplay of green and brown webs during salt marsh succession

Schrama M, van der Plas F, Berg MP, Olff H (2017) Decoupled diversity dynamics in green and brown webs during primary succession in a saltmarsh. J Anim Ecol 86:158-169. https://doi.org/10.1111/1365-2656.12602

Shaw RG, Etterson JR (2012) Rapid climate change and the rate of adaptation: Insight from experimental quantitative genetics. New Phytol 195:752-765

Slade AJ, Hutchings MJ (1987) The effects of nutrient availability on foraging in the clonal herb glechoma hederacea. J Ecol 75:95-112

Tillman D (1985) The resource-ratio hypothesis of plant succession. Am Nat 125:827-852. https://doi.org/10.1086/ 284382

Tilman D (1987) Secondary succession and the pattern of plant dominance along experimental nitrogen gradients. Ecol Monogr 57:190-214

Turley NE, Odell WC, Schaefer H, Everwand G, Crawley MJ, Johnson MTJ (2013) Contemporary evolution of plant growth rate following experimental removal of herbivores. Am Nat. https://doi.org/10.1086/668075

Van Der Graaf AJ, Stahl J, Bakker JP (2005) Compensatory growth of Festuca rubra after grazing: can migratory herbivores increase their own harvest during staging? Funct
Ecol 19:961-969. https://doi.org/10.1111/j.1365-2435. 2005.01056.x

Van Der Wal R, van Wijnen H, van Wieren S, Beucher O, Bos D (2000) On Facilitation between Herbivores: How Brent Geese Profit from Brown Hares. Ecology 81:969-980

Van Klink R, Nolte S, Mandema FS, Lagendijk DDG, WallisDeVries MF, Bakker JP, Esselink P, Smit C (2016) Effects of grazing management on biodiversity across trophic levels-the importance of livestock species and stocking density in salt marshes. Agric Ecosyst Environ 235:329-339. https://doi.org/10.1016/j.agee.2016.11.001

Veeneklaas R, Bockelmann A, Reusch T, Bakker J (2011) Effect of grazing and mowing on the clonal structure of Elytrigia atherica: a long-term study of abandoned and managed sites. Preslia 83:455-470

Veeneklaas RM, Dijkema KS, Hecker N, Bakker JP (2013) Spatio-temporal dynamics of the invasive plant species Elytrigia atherica on natural salt marshes. Appl Veg Sci 16:205-216. https://doi.org/10.1111/j.1654-109X.2012. 01228.x

Völler E, Bossdorf O, Prati D, Auge H (2017) Evolutionary responses to land use in eight common grassland plants. J Ecol 105:1290-1297. https://doi.org/10.1111/1365-2745. 12746

Wang C, Tang Y (2019) A global meta-analyses of the response of multi-taxa diversity to grazing intensity in grasslands. Environ Res Lett 14:114003. https://doi.org/10.1088/17489326/ab4932

Wanner A, Suchrow S, Kiehl K, Meyer W, Pohlmann N, Stock M, Jensen K (2014) Scale matters: impact of management regime on plant species richness and vegetation type diversity in Wadden Sea salt marshes. Agric Ecosyst Environ 182:69-79. https://doi.org/10.1016/j.agee.2013. 08.014

Weiner J, Martinez S, Muller-Scharer H, Stoll P, Schmid B (1997) How Important are Environmental Maternal Effects in Plants? A Study with Centaurea Maculosa. J Ecol 85(2):133

Zeileis A, Kleiber C, Jackman S (2008) Regression models for count data in R. J Stat Softw 27:1-25

Zuppinger-Dingley D, Schmid B, Petermann JS, Yadav V, De Deyn GB, Flynn DFB (2014) Selection for niche differentiation in plant communities increases biodiversity effects. Nature 515 (7525):108-111

Publisher's Note Springer Nature remains neutral with regard to jurisdictional claims in published maps and institutional affiliations. 